\title{
Proceeding
}

Supplementary Issue: Spring Conferences of Sports Science. Costa Blanca Sports Science Events, 14-15 June 2019. Alicante, Spain.

\section{Relationship between motor learning and reaction capacity in motor task}

\author{
FELICE DI DOMENICO ${ }^{1}$, SIMONA FATTORE ${ }^{1}$, SALVATORE PIGNATO², TIZIANA D'ISANTO ${ }^{1}$ \\ 1 University of Salerno, Italy \\ 2University Kore of Enna, Italy
}

\begin{abstract}
The aim of the study is to measure the ability to react to a specific stimulus, which in this study can be acoustic or visual. The acquired data allowed us to evaluate two parameters, called: reaction time and action time. The test considers movement in its entirety, trying to identify the mechanisms that allowed the creation of the gesture, even going back to the sensitive phases of motor learning. The various capacities that contribute to the structure of a given motor gesture are considered as inseparable elements of a single project that, in a continuous and non-linear way, influence each other. The method is an experimental research through the recruitment of data with questionnaires and surveys prepared with the Google Forms platform and the evaluation of motor gestures with a technological tool: Optojump Next. The sample is represented by a group of 25 students of the three-year bachelor's degree in Exercise Science from the University of Salerno, aged between 20 and 27 years. The results of the initial data confirm the impossibility of breaking down the movement into simpler parts in order to understand how it works because it emerges that the movement must be considered in its entirety. The integrated use of quantitative biomechanical and qualitative educational evaluation can be achieved with self-assessment and enabled self-esteem. The results seem to confirm the close relationship between skills possessed and learned in the appropriate stages. In conclusion, the study can be useful to identify performance's area to be analysed in order to form the motor-sporting educational professional skills most dedicated to evaluation. Keywords: Self-perception; Reaction capacity; Optojump; Strength; Coordination; Complex systems.
\end{abstract}

\section{Cite this article as:}

Di Domenico, F., Fattore, S., Pignato, S., \& D'Isanto, T. (2019). Relationship between motor learning and reaction capacity in motor task. Journal of Human Sport and Exercise, 14(4proc), S1030-S1037. doi:https://doi.org/10.14198/jhse.2019.14.Proc4.65

Corresponding author. University of Salerno, Italy.

E-mail: flcdidomenico@gmail.com

Supplementary Issue: Spring Conferences of Sports Science. Costa Blanca Sports Science Events, 14-15 June 2019. Alicante, Spain.

JOURNAL OF HUMAN SPORT \& EXERCISE ISSN 1988-5202

(c) Faculty of Education. University of Alicante

doi:10.14198/jhse.2019.14.Proc4.65

S1030 | 2019| Proc4 | VOLUME 14

C 2019 University of Alicante 


\section{INTRODUCTION}

The Reaction Capacity allows us to react as quickly as possible to stimuli: visual, auditory, tactile ... (Anderlini, 2015). The Reaction Capacity is not limited to sports activities (Alminni et al, 2019, Cirillo et al, 2016) alone but is used constantly during daily actions (D'Isanto et al., 2019, Ferrara et al, 2019, Forte et al, 2019, Valentini et al, 2019, Raiola, 2017, 2014, 2013), just think of when we are driving and we have to brake or swerve suddenly or when a glass is about to fall at home, our ability to react avoid damage (Bobat, Bobat, 2015, Bosch, Cook, 2015, Bompa, Buzzichelli, 2014).

\section{Processing \\ 3. Motor output}

1. Sensory perception

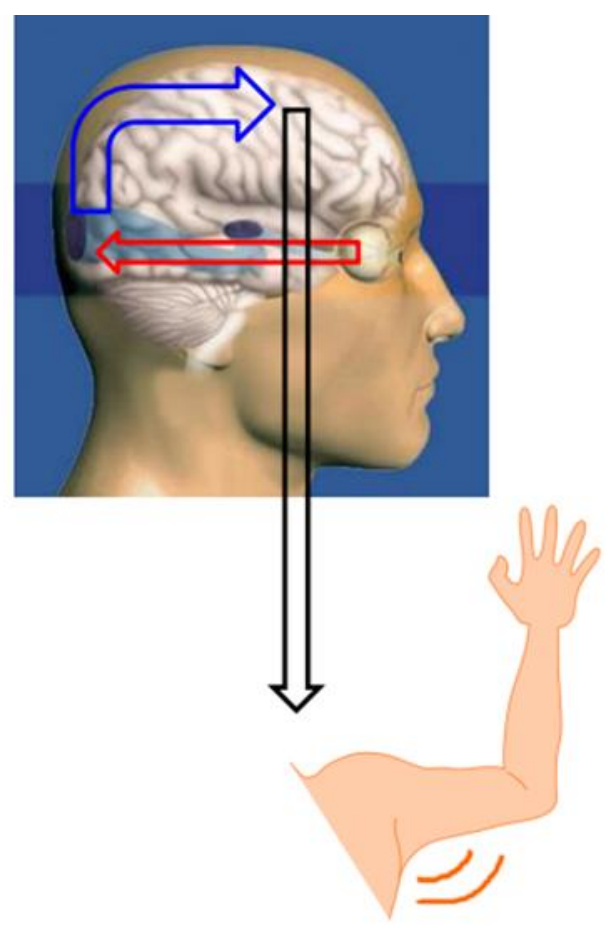

Figure 1. Action scheme.

The reaction time is composed of a total time during which there is the perception, identification and processing of an external stimulus and finally the motor response (Vealey, Chase, 2016, Weineck, 2009, Meraviglia, 2012); the total time is divided in turn into reaction time and movement time (Pisano et al, 2019, Pisapia et al, 2019, Bosch, Cook, 2015). There are simple and complex reactions (D'elia, 2019, D'elia et al 2019, Altavilla et al, 2018). By simple reactions we mean movements that are characterized by the movement of a very small part of the body; for example, pushing a button with the hand or foot. Complex reactions include movements that involve an important part or the whole body: this is the case, for example, of swift 5 $\mathrm{m}$ runs, short starting movements from various positions, and short snap movements connected with coordination tasks to be performed very quickly (Zatsiorsky, Kraemer, 2006) Paavo,1991, Invernizzi et al, 2019). Simple reactions are regulated for the most part by processes of genetic dominance, in complex reactions they mainly influence social factors such as training. In the study in question the acoustic reaction and the optical reaction, both single and combined, was evaluated. Acoustic Reaction: the stimulus is represented by a beep or a recorded sound. Optical reaction: the optical stimulus is represented by the change in the colour of the PC screen or by the variation of an external traffic light (Gambetta, 2011, Brown, Ferrigno, 2005). The aim of the study is that of evaluating the ability to react in a sample of students of the faculty of sport sciences of the University of Salerno (Sanseviero et al., 2019ab) in order to estimate the level 
of these qualities and try to identify the determining factors for their development and improvement. By relating the results obtained with other qualitative and quantitative data obtained through a questionnaire drawn up with the Google Forms platform, it was possible to trace a possible learning path that led to the acquisition and consolidation of these skills.

\section{METHODS, TOOLS AND RESEARCH SAMPLE}

The realization of the study has developed through the succession of some procedures:

- Sample selection;

- Sending the online questionnaire to find data on the current and past motor-sports habits of the evaluated subject (Caselli, 2005);

- Identification of the statistical units with assignment of an identification code;

- Test execution with specific instrumentation;

- Data recording;

- Data analysis;

- Conclusions.

The tools used for the realization of this work have been carefully selected:

- Informed consent signed by the students undergoing the study;

- Questionnaire written on Google Forms administered before the actual evaluation;

- OptoJump Next instrumentation, supplied by the University;

Other accessory tools used in the tests were: chronometer, pc, cameras.

The research sample is represented by a group of students from the University of Salerno, attending the second year of the three-year degree in "Sciences of physical activity, sports and psychomotor education". In particular, we are talking about 25 students aged between 20 and 27 years. Anthropometric and personal data were collected on these subjects: age, height, weight. Furthermore, for each of them an identification code was generated consisting of five digits obtained from the last three digits of the university matriculation number and the first initial of the surname and name. These data were obtained by submitting the statistical units, after signing the informed consent, to a questionnaire prepared by the Google Forms platform. The Google Forms platform allowed us to find qualitative and quantitative data on the previous and current motor experiences of the statistical units and, if athletes, the level of practice of the sport indicated (weekly training sessions, duration of training sessions, etc.)

\section{DATA COLLECTION AND ANALYSIS. OPTO-ACOUSTIC REACTION}

\section{Aim}

The opto-acoustic reaction test has the objective of measuring the reaction times to a stimulus that can be both optical and acoustic.

\section{Procedure}

In the study in question we used the Opto-Acoustic Reaction test in which the Optical / Acoustic stimulus is not specified, and the athlete must react to both stimuli. The subject is positioned straddling a bar with one 
foot out and the other inside the circumference circumscribed by the bars placed in parallel; at the signal the subject must lift the foot.

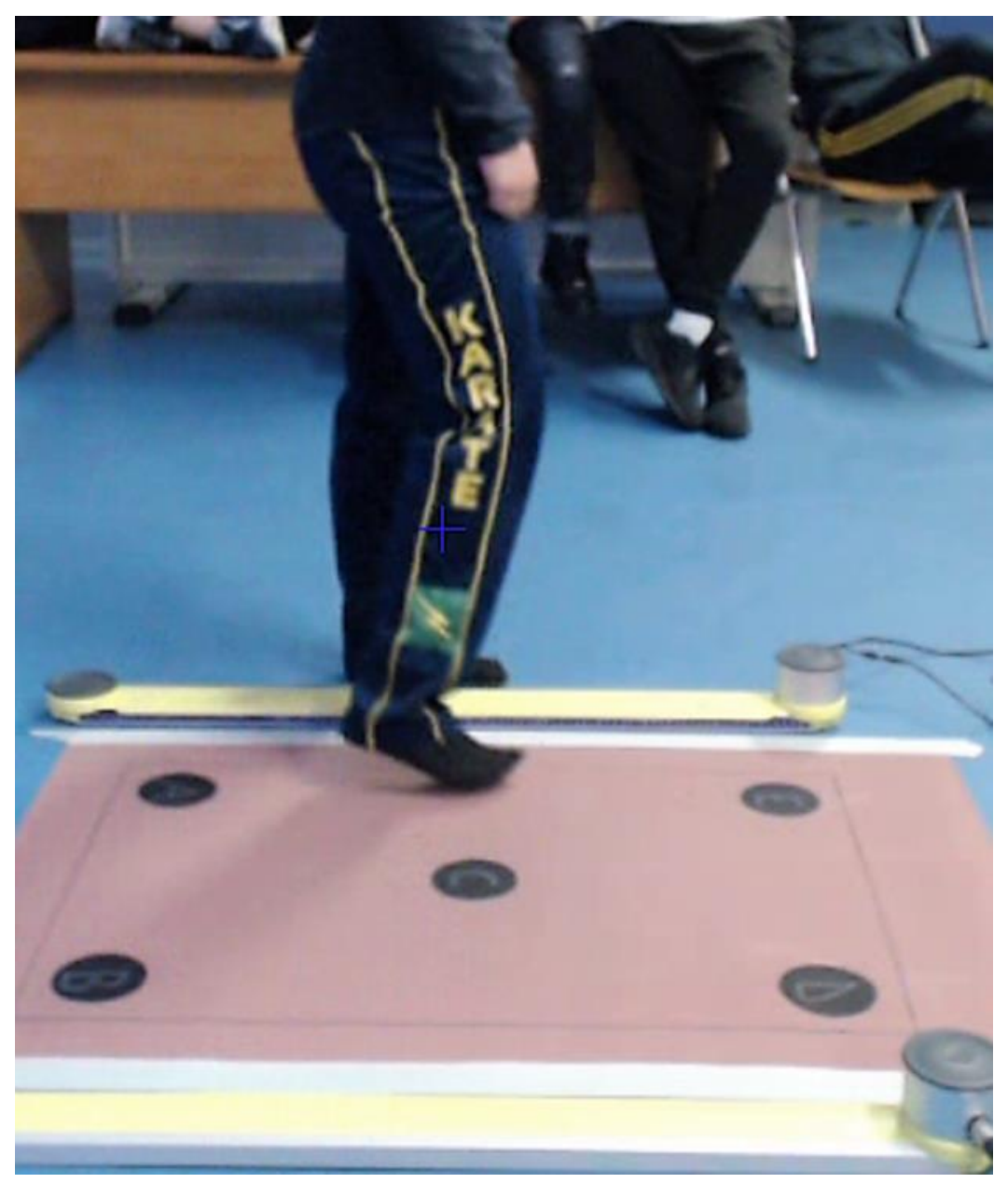

Figure 2. Opto-Acoustic Reaction test.

\section{RESULTS}

From the analysis of the results of this test two types of information can be deduced, the first concerning the speed of reaction, the other pertaining to the speed of action.

The speed of reaction represents the capacity of the CNS to discriminate and elaborate the adequate response after having acquired and processed the stimuli of various nature coming from the environment. In consideration of this parameter, this test also indicates the efficiency of one analyser compared to another. The speed of action follows the reaction phase to quickly build a single intentional gesture in its entirety. The results obtained from the test are shown in a table below. The results obtained, the result of different anthropometric and athletic characteristics, gave interesting indications on the relationship between the motor experience and the physical characteristics of the tested subject and the result obtained. 
Table 1. Speed of reaction and of action

\begin{tabular}{|c|c|c|c|c|c|c|c|c|c|c|c|}
\hline \multirow[b]{2}{*}{ \# } & \multirow[b]{2}{*}{ ATHLETE } & \multirow[b]{2}{*}{ AGE } & \multirow[b]{2}{*}{ WEIG } & \multirow[b]{2}{*}{ SEX } & \multirow[b]{2}{*}{ SPORT } & \multicolumn{3}{|c|}{ RIGHT LEG } & \multicolumn{3}{|l|}{ LEFT LEG } \\
\hline & & & & & & RT & $\mathbf{F T}$ & HEIGHT & RT & $\mathbf{F T}$ & HEIGHT \\
\hline 1 & 469GI & 20 & 53 & $\mathrm{~F}$ & None & 0,471 & 0,417 & 21,5 & 0,583 & 0,381 & 17,8 \\
\hline 2 & 483BA & 22 & 78 & $M$ & Football & 0,419 & 0,289 & 10,9 & 0,442 & 0,417 & 21,5 \\
\hline 3 & 483EG & 20 & 83 & $\bar{M}$ & Football & 0,473 & 0,228 & 6,4 & 0,426 & 0,343 & 14,5 \\
\hline 4 & 494BR & 20 & 54 & M & Cycling & 0,557 & 0,204 & 5,2 & 0,807 & 0,22 & 6 \\
\hline 5 & 501DV & 21 & 57 & $\mathrm{~F}$ & Volleyball & 5,11 & 0,212 & 5,5 & 0,532 & 0,263 & 8,7 \\
\hline 6 & 512PL & 22 & 66 & $\bar{M}$ & Swim/Karate & 0,497 & 0,173 & 3,7 & 0,52 & 0,198 & 4,9 \\
\hline 7 & $530 \mathrm{DM}$ & 20 & 56 & $\mathrm{~F}$ & Dance & 0,458 & 0,393 & 19,5 & 0,607 & 0,412 & 20,9 \\
\hline 8 & $536 \mathrm{LS}$ & 20 & 60 & $\mathrm{~F}$ & Volleyball & 0,621 & 0,343 & 14,4 & 0,551 & 0,358 & 16,6 \\
\hline 9 & 544IF & 21 & 60 & $\bar{M}$ & Football & 0,448 & 0,126 & 2,1 & 0,453 & 0,134 & 2,3 \\
\hline 10 & 548PV & 24 & 75 & $M$ & Boxing & 0,453 & 0,134 & 2,3 & 0,452 & 0,252 & 7,8 \\
\hline 11 & 553IM & 21 & 47 & $F$ & Futsal & 0,447 & 0,16 & 3,2 & 0,452 & 0,192 & 4,6 \\
\hline 12 & $560 \mathrm{PC}$ & 20 & 70 & $\bar{M}$ & Basket & 0,466 & 0,095 & $\overline{1,1}$ & 0,493 & 0,113 & 1,6 \\
\hline 13 & $562 \mathrm{NC}$ & 21 & 105 & $\bar{M}$ & Football & 0,436 & 0,317 & 12,4 & 0,428 & 0,344 & 14,7 \\
\hline 14 & $563 \mathrm{MF}$ & 20 & 65 & $\mathrm{~F}$ & Volleyball & 0,484 & 0,111 & 1,6 & 0,504 & 0,142 & 2,6 \\
\hline 15 & $615 \Pi$ & 20 & 65 & $\bar{M}$ & Soccer referee & 0,444 & 0,128 & 2,1 & 0,537 & 0,181 & 4,1 \\
\hline 16 & 624FM & 26 & 78 & $\mathrm{~F}$ & Body building & 0,484 & 0,311 & 12 & 0,427 & 0,389 & 18,6 \\
\hline 17 & 635DN & 20 & 62 & $\bar{M}$ & Football & 0,401 & 0,12 & 1,8 & 0,434 & 0,055 & 0,4 \\
\hline 18 & 639CE & 24 & 57 & $\mathrm{~F}$ & Volleyball & 0,463 & 0,134 & 2,2 & 0,49 & 0,101 & 1,3 \\
\hline 19 & $652 \mathrm{FA}$ & 20 & 57 & $\bar{M}$ & Athletics & 0,616 & 0,151 & 2,8 & 0,567 & 0,151 & 2,8 \\
\hline 20 & $656 \mathrm{MG}$ & 20 & 82 & $\bar{M}$ & Body building & 0,633 & 0,349 & 15 & 0,606 & 0,364 & 16,2 \\
\hline 21 & $786 \mathrm{MR}$ & 22 & 84 & $M$ & Football & 0,431 & 0,138 & 2,4 & 0,463 & 0,19 & 4,5 \\
\hline 22 & 788LA & 20 & 58 & $\mathrm{~F}$ & Basket & 0,473 & 0,134 & 2,4 & 0,556 & 0,07 & 0,7 \\
\hline 23 & 791AV & 25 & 45 & $\mathrm{~F}$ & Athletics & 0,551 & 0,218 & 6,1 & 0,649 & 0,251 & 7,8 \\
\hline 24 & $798 \mathrm{GA}$ & 20 & 64 & $F$ & Rugby/Karate & 0,549 & 0,198 & 4,8 & 0,548 & 0,198 & 5 \\
\hline & 851VD & 20 & 60 & $F$ & Volleyball & 0,399 & 0,166 & 3,4 & 0,421 & 0,186 & 4,3 \\
\hline & & & & & AVERAGE & 0,502 & 0,225 & 7,6 & \multirow{3}{*}{\multicolumn{2}{|c|}{$\begin{array}{l}\text { RT=REACTION TIME } \\
\text { FT=FLIGHT TIME }\end{array}$}} & \\
\hline & & & & & MINIMUM & $\# 25-0,399$ & $\# 17-0,055$ & $\# 17-0,4$ & & & \\
\hline & & & & & MAXIMUM & $\# 4-0,807$ & $\# 1-0,417$ & $\# 1-21,5$ & & & \\
\hline
\end{tabular}

\section{DISCUSSION}

Analysing the reaction times, that is the time between the stimulus and the beginning of the motor task, the best results were obtained by $851 \mathrm{VD}$, a female athlete who also distinguished herself in the previous test. His time was 0.399 seconds for the right leg and 0.421 seconds for the left leg. The reaction times of 635DN, a former 20-year-old male athlete, $183 \mathrm{~cm}$ tall and weighing $62 \mathrm{~kg}$, should also be considered. His sport, played at a competitive level for 11 years, was football. He did 3 workouts a week that lasted 1-2 hours on average. During the age groups from infancy to adolescence he has always preferred to play "backyard games / outdoor activities" with weekly frequencies from 4-6 hours, up to 6 years, 7 hours and more, from 10 to 13 years. It is not in progress with university exams and its average is $23-26 / 30$. The reaction times obtained in the test were $0.401 \mathrm{sec}$ for the right leg and $0.434 \mathrm{sec}$ for the left leg. The worst results, in terms of reaction times higher than the average of the participants, were obtained from 494BR, a male subject, 20 years old, $152 \mathrm{~cm}$ tall and weighing $54 \mathrm{~kg}$. This is a non-competitive level cycling athlete for 6 years. On average, 3 training sessions per week of more than two hours are practiced for this activity. Previously, from 7 years to 14 years, he practiced Kung Fu at a non-competitive level. he practiced 2 weekly training sessions for this sporting activity. His motor experiences give us a fairly sedentary profile in the age group from 3 to 9 years, privileging as an activity "watching TV / playing video games", practicing them with a weekly frequency of 4-6 hours. From 10 to 13 years of age the privileged physical activity was "playground / outdoor activities" which he practiced every week for 4-6 hours. It does not appear to be in progress with university exams and 
its average is $18-22 / 30$. The reaction times obtained in the test were $0.557 \mathrm{sec}$ for the right leg and 0.807 sec for the left leg.

The speed of action indicates the total time to make a complete movement and is expressed in distance I time. The determining factors for this parameter are the flight time, that is the time taken to complete the entire movement and the height of the lift, that is the amplitude of the movement. For the calculation of this parameter we refer to the definition of power, that is the speed with which the work is done. The formula is as follows:

$$
\text { Power }=(\text { work done }) /(\text { time interval })=\mathrm{L} / \mathrm{t}
$$

The best results with respect to this parameter were found on $469 \mathrm{GI}$ and $530 \mathrm{DM}$, which completed the excursion of their movement in the shortest possible time.

$469 \mathrm{Gl}$ is a female subject, $160 \mathrm{~cm}$ tall and weighing $53 \mathrm{~kg}$, not practicing any sport. From 3 to 13 years he has always practiced "backyard games / outdoor activities" with a frequency of about 7 hours a week up to 9 years and 4-6 hours from 10 years. She is in compliance with university exams with an average of 27-30 / 30. The average flight time with the right leg was 0.417 seconds reaching a height of $21.5 \mathrm{~cm}$, while with the left leg the flight time was 0.381 seconds for a height of $17.8 \mathrm{~cm}$.

$530 \mathrm{DM}$ is a 20 -year-old female subject, $167 \mathrm{~cm}$ tall and weighing $52 \mathrm{~kg}$. From 15 years, from the age of 5 , he is a non-competitive level athlete in dance: he performs 5 weekly training sessions of an average duration of 1 hour. From the age of 3 to 5 , he preferred to play "backyard games / outdoor activities" with a weekly frequency of 4-6 hours; from 6 to 9 years he preferred to devote himself to "watching TV / playing video games" with a weekly frequency of 4-6 hours; from 10 to 13 years he preferred to practice "activities in the countryside" with a weekly frequency of 4-6 hours. It turns out not to be underway with university exams, with an average of 23-26 / 30. His flight time was 0.393 seconds reaching a height of $19.5 \mathrm{~cm}$ with the right leg and 0.412 seconds reaching a height of $20.9 \mathrm{~cm}$ with the left leg. The worst results are found in 635DN, having obtained for the right leg a flight time of 1.8 seconds and a height of $0.8 \mathrm{~cm}$, while, for the left leg, a flight time of 0.055 seconds and a height of $0.4 \mathrm{~cm}$. 635DN is 20 years old, weighs $62 \mathrm{~kg}$ and is $183 \mathrm{~cm}$ tall. $\mathrm{He}$ is a former competitive level athlete. His sport was football, which he practiced for 11 years, from 6 years of age. On average, he performed 3 training sessions per week from 1-2 hours per session. From the age of 3 to 13 he has privileged "playground games / outdoor activities" with a weekly frequency that from 10 years was 7 hours and more. It is not in progress with university exams and its average is 23-26 / 30 .

\section{CONCLUSIONS}

From the analysis of the results obtained from the test protocol it has been highlighted how various factors of various nature contribute to the realization of a gesture of any kind. Therefore, we will have subjects that, in performing a given motor task, albeit for the first time, will achieve positive results because they have learned skills in the past that they can reuse by adapting them to the task (Andorlini, 2015). Motor development takes place incessantly throughout life. This mechanism is due to hereditary genetic heritage, experiences and the environment (Schmidt, Lee, 2012).

The development of good reaction skills can significantly influence the realization of a motor action, which can refer to simple actions of daily life, or to competitive actions. The study in question has shown that the 
best results in terms of reaction times and flight times have been obtained by subjects who, in the sports they practice, solicit these abilities in a decisive manner.

\section{REFERENCES}

Alminni C., Altavilla, G., Cassese, F.P., Ceciliani, A., D'isanto, T. (2019) Physical and motor tests to estimate the improvement of the float serve, Journal of Human Sport and Exercise, 14 (Proc2), pp. S245-S250. https://doi.org/10.14198//hse.2019.14.proc2.13

Altavilla, G., D'isanto, T., Di Tore, P.A. (2018) Anthropometrics characteristics and jumping ability in basketball, Journal of Human Sport and Exercise, 13, pp. S385-S392. https://doi.org/10.14198//hse.2018.13.proc2.22

Andorlini A., (2015) Pre-correre i tempi. Dalla teoria delle idee all'esercizio dei movimenti, Strenght \& Conditioning, anno IV - n. 13/Luglio/settembre.

Bobath B., Bobath K., (2015) Lo sviluppo motorio nei diversi tipi di paralisi cerebrale, Sorbello.

Bompa T., Buzzichelli C. A., (2017) Periodizzazione dell'allenamento sportivo, Calzetti Mariucci, PG.

Bosch F, Cook K., (2015) Strength training and coordination: an integrative approach, Uitgevers.

Boyle M., (2018) Allenamento funzionale applicato allo sport, Olympians, Fl.

Brown L. E., Ferrigno V., (2005) Training for Speed, Agility, and Quickness, Human Kinetics, UK.

Caselli M., (2005) Indagare col questionario: introduzione alla ricerca sociale di tipo standard, Vita e pensiero, Milano.

Cirillo, G., Nughes, E., Acanfora, A., Altavilla, G., D'Isanto, T. (2016) Physical and sport education testing by quantitative and qualitative tools in assessment in senior school: A proposal, Sport Science, 9, pp. 97-101.

D‘Elia, F. (2019). The training of physical education teacher in primary school. Journal of Human Sport and Exercise, 14(1proc), S100-S104. https://doi.org/10.14198/ihse.2019.14.Proc1.12

D'Elia, F., D'Isanto, T., \& Altavilla, G. (2019). Training and performance in the transition period. Journal of Human Sport and Exercise, 14(2proc), S258-S262.

https://doi.org/10.14198/ihse.2019.14.Proc2.15

D'Isanto, T., D'Elia, F., Raiola, G., Altavilla, G. (2019) Assessment of sport performance: Theoretical aspects and practical indications, Sport Mont, 17 (1), pp. 79-82.

D'isanto, T., Di Tore, P.A., Altavilla, G. (2018) Correlation of the anthropometric characteristics and the ability to jump in volleyball, Journal of Human Sport and Exercise, 13, pp. S393-S400. https://doi.org/10.14198//hse.2018.13.proc2.23

Ferrara, F., Izzo, R., Ceciliani, A., Di Tore, A.P. (2019) Pilot study on the testing of Power Glove. applied to volleyball, Journal of Human Sport and Exercise, 14 (Proc2), pp. S233-S238. https://doi.org/10.14198/ihse.2019.14.proc2.11

Forte, D., Ceciliani, A., Izzo, R., Altavilla, G. (2019) Transition period: Pilot study on performance reduction of ability to jump in volleyball, Journal of Human Sport and Exercise, 14 (Proc2), pp. S221S227. https://doi.org/10.14198/ihse.2019.14.proc2.09

Gambetta V., (2011) Following The Functional Path, Momentum Media Sports, USA.

Invernizzi, P.L., Scurati, R., Crotti, M., Bosio, A., Longo, S., Esposito, F. (2019) Physiological and technical commitment during a $300-\mathrm{m}$ in-line skating trial in athletes of different age categories, Journal of Sports Medicine and Physical Fitness, pp. 25-34. https://doi.org/10.23736/s00224707.18.07942-2

Meraviglia V., (2012) Sistemi motori: Nuovi paradigmi di apprendimento e comunicazione, SpringerVerlag, Milano. https://doi.org/10.1007/978-88-470-1995-9_7

Weineck J., (2009) L'allenamento ottimale, Calzetti Mariucci, Perugia. 
Paavo K., (1991) Strenght and power in sport. Wiley publication.

Raiola, G. (2017) Motor learning and teaching method, Journal of Physical Education and Sport, 17, art. no. 236, pp. 2239-2243.

Raiola, G. (2014) Motor control and learning skills according to cognitive and ecological dynamic approach in a vision on behaviorism, cognitive, Gestalt and phenomenology theories, Mediterranean Journal of Social Sciences, 5 (15), pp. 504-506. https://doi.org/10.5901/mjss.2014.v5n15p504

Raiola, G. (2013) Body knowledge and motor skills, Knowledge Cultures, 1 (6), pp. 64-72.

Schmidt R., Lee T., (2012) Controllo motorio e apprendimento, Calzetti Mariucci, PG.

Sanseviero, I., Cassese, F.P., Fonzo, E., Altavilla, G., D'elia, F. (2019a) Study on the master's degree in sciences of sports evaluation and sport for disabled at the University of Salerno, Italy. Journal of Human Sport and Exercise, $14 \quad$ (Proc2), pp. S239-S244. https://doi.org/10.14198/ihse.2019.14.proc2.12

Valentini, M., Riccardi, F., Raiola, G., Federici, A. (2018) Educational research: Motor area and relational area during children's personality development, Journal of Physical Education and Sport, 18, art. no. 327, pp. 2157-2174.

Zatsiorsky V. M., Kraemer W. J., (2006) Science and Practice of Strength Training, Human Kinetics.

\section{(요요}

This work is licensed under a Attribution-NonCommercial-NoDerivatives 4.0 International (CC BY-NC-ND 4.0). 